\title{
THE REACTIVITY OF THE CAPILLARY BED OF THE NAILFOLD TO CIRCULATING EPINEPHRINE AND NOR-EPINEPHRINE IN PATIENTS WITH NORMAL BLOOD PRESSURE AND WITH ESSENTIAL HYPERTENSION
}

\author{
By SHELDON E. GREISMAN \\ (From the Department of Medicine, New York University College of Medicine and the Third \\ [New York University] Medical Division, Bellevue Hospital, New York, N. Y.)
}

(Submitted for publication January 24, 1952; accepted June 20, 1952)

Several studies have attempted to determine whether the vascular system of patients with essential hypertension is hyper-reactive to epinephrine. In these studies vascular reactivity was judged solely by the increase in arterial blood pressure following the parenteral administration of this pressor substance. Some investigators believed that this method indicated vascular hyperreactivity to epinephrine in patients with essential hypertension; others concluded that the vascular reactivity remained within the normal range (17).

Epinephrine does not alter blood pressure by a single mechanism. Some vascular beds (skin and splanchnic area) are constricted, others (muscular) are dilated by the drug. The resultant change in the overall peripheral resistance depends upon which effect predominates. Epinephrine also acts directly upon the heart, and increases the cardiac output. Alteration of blood pressure following epinephrine administration is therefore a resultant of the changes of three separate mechanisms-vasoconstriction, vasodilatation, and cardiac output. A hyper-reactivity to epinephrine of those vascular beds that react by vasoconstriction may be masked if blood pressure changes are employed as the sole criteria of vascular reactivity.

An approach which would assay vasoconstrictor reactivity alone consists of direct observation of the changes produced in the caliber of the lumen of the minute vessels when pressor substances are injected. This approach entails several major disadvantages: 1 ) the number of capillary beds accessible for examination in the intact individual is limited to those located peripherally; 2) small variations in the diameter of the individual vessel, which could appear insignificant, might actually be significant, when multiplied by the tremendous number of vessels involved in a similar response;
3) a vascular bed which is already partially or fully constricted would show little or no change in response to a pressor substance regardless of its intrinsic reactivity.

The last two difficulties are minimized by observing the narrowest contractile elements of the minute vascular bed. A slight constriction of these vessels markedly reduces the stream of red blood cells flowing distally and produces a readily visible effect, ischemia of the capillary bed. If the capillary bed is already partially or fully constricted, ischemia is noted and injection of the pressor substances is withheld.

It has recently been demonstrated that the precapillaries and metarterioles of the bulbar conjunctiva have fairly definite ranges of reactivity to topically applied epinephrine, and that in individuals with normal blood pressure the ranges are different from patients with essential hypertension. In patients with essential hypertension these minute vessels were found to be hyper-reactive to topically applied epinephrine. Only the vascular bed of the bulbar conjunctiva of individuals in the upright position was studied $(8,9)$.

The present study was undertaken to determine whether the reactivity of a minute vascular bed to circulating epinephrine and nor-epinephrine differed significantly in patients with normal blood pressure from patients with essential hypertension. The capillary bed of the nailfold of the finger was selected for observation.

\section{METHOD}

Ward patients with normal blood pressures and those with essential hypertension were selected for study. $\mathrm{Pa}$ tients with associated disease states that independently might have altered the peripheral vascular reactivity were usually excluded. This applied to subjects with an abnormal blood volume, cardiac output, or peripheral circulation, and to those receiving medications known to 
induce vasomotor changes. The patients were recumbent for at least one-half hour, or until their blood pressures had stabilized. A needle with a three-way stopcock was inserted into the antecubital vein of one arm. A tuberculin syringe was attached to this arrangement so that calibrated doses of pressor substances could be injected intravenously without the knowledge of the patient. The other arm was kept approximately 30 degrees from the side with the fingertips at the level of the sternum and steadied by a clamp applied to the lateral margins of the distal phalanx. Cedar oil was applied to the surface of the nailfold and the capillary microscope focused upon the terminal capillary loops which were illuminated by means of a slit lamp. The capillary bed was then examined until two adjacent capillary loops with arterial segments approximately 8 microns in diameter were found. These were selected for observation. Graded doses of one of the pressor substances, epinephrine 1 (E), levoepinephrine $^{2}$ (E1), or levo nor-epinephrine ${ }^{3}$ (N) were then injected intravenously in increments of 0.25 to 0.50 gamma approximately every five minutes until vasoconstriction, recognized by a definite ischemia of the arterial segments of these two loops, persisted for at least 15 seconds. The same dose was then reinjected five minutes later to determine the reproducibility of the effect. When the repeat injection occasionally failed to produce the same result, the injections were continued with progressively larger quantities until a reproducible effect was obtained. This quantity was recorded as the "threshold" epinephrine capillary reactivity.

The rate of injection was kept as uniform as possible at $0.4 \mathrm{cc}$. per second, the volume usually not exceeding $0.8 \mathrm{cc}$. The epinephrine and nor-epinephrine solutions were freshly prepared prior to injection and so constituted that $1 \mathrm{cc}$. always contained 2.5 gamma of the free base in isotonic saline.

Reflex vasodilatation was not employed. However, special attention was paid to the temperature and color of the extremities which, together with direct observations of the rate of blood flow in the capillaries, the degree of clumping of the red blood cells, and the circulation time, served as a satisfactory index of the adequacy of peripheral capillary flow. The circulation time was measured from the moment of injection of epinephrine into the antecubital vein to the initiation of ischemia of the capillary loops of the nailfold.

\section{RESULTS}

The anatomy of the capillary bed of the nailfold has been described previously (10). The terminal capillary loops were usually clearly visualized.

\footnotetext{
1 Hydrochloride salt (extract of adrenal medulla; supplied by Parke, Davis \& Co.).

2 Bitartrate salt (synthetic; supplied by WinthropStearns, Inc.).

${ }^{3}$ Bitartrate salt (synthetic; supplied by WinthropStearns, Inc.).
}

The arterial segment of each capillary loop manifested independent and intermittent vasoconstriction, during which ischemia of the arterial segment occurred. This intermittent and independent vasoconstriction of the capillary bed is known as "vasomotion" (11-13). In patients with normal arterial blood pressure and in those with essential hypertension the duration of the constricted phase of this normal vasomotion process was brief, usually less than two seconds. The frequency of vasoconstriction varied markedly even in the same capillary loop. The majority of the capillary loops in patients with normal blood pressure remained patent with a fairly steady rate of blood flow and with only occasional vasoconstriction. In patients with essential hypertension, exposed to similar room temperatures and with comparably warm hands to the touch, there was usually an increase in the frequency of constriction of the arterial segments of the capillary loops. The interval between the constricted phases would occasionally be as brief as five seconds. A similar increased vasomotion has been described in the minute vascular bed of the bulbar conjunctiva of individuals with essential hypertension (9).

The intravenous injection of epinephrine and nor-epinephrine appeared to intensify the normal vasomotion process. As the quantity of epinephrine or nor-epinephrine injected was increased, the duration and the frequency of the constriction of the arterial segment of each capillary loop increased. The duration of the vasoconstriction usually increased slightly, rarely more than five seconds. The frequency of vasoconstriction, however, increased progressively so that the dilated phase intervened only by fractions of one second between the constricted phases. A virtually persistent ischemia of the arterial segment of the capillary loop was therefore produced, the duration of which depended upon the quantity of epinephrine or nor-epinephrine injected. The ischemia of the arterial segments of the capillary loops produced by the injection of epinephrine or norepinephrine could be distinguished from that occurring as the result of normal vasomotion by these characteristics: 1 ) the ischemia began within the expected circulation time of arm to finger, 15 to 22 seconds ; 2) the ischemia occurred concomitantly in the adjacent capillary loops; 3 ) the rate of blood flow through the capillary loops increased 


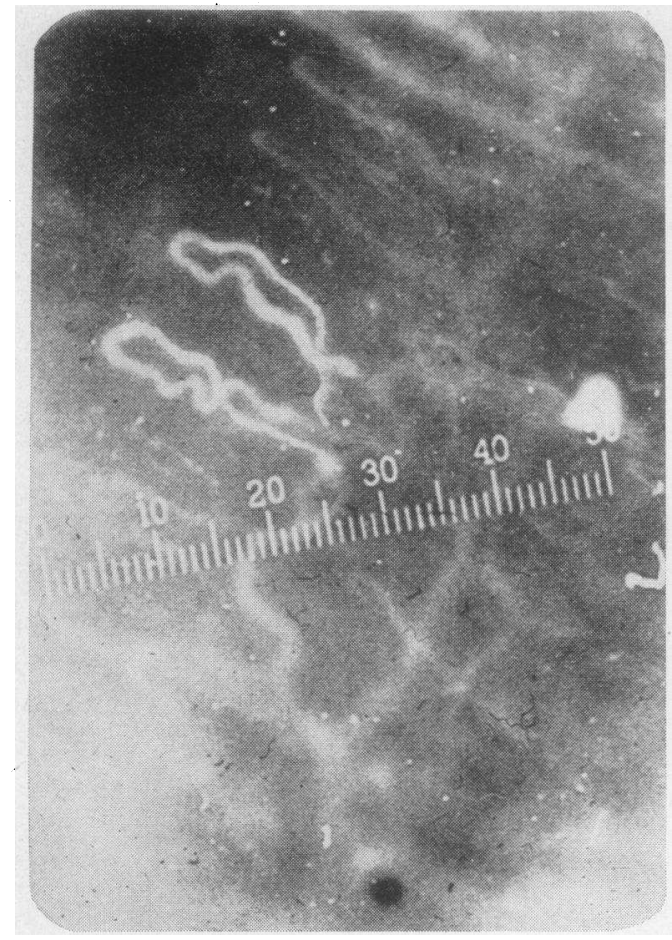

Fig. 1. Capillary Bed of the Nailfold of a Patient with Normal Blood Pressure $(80 \times)$

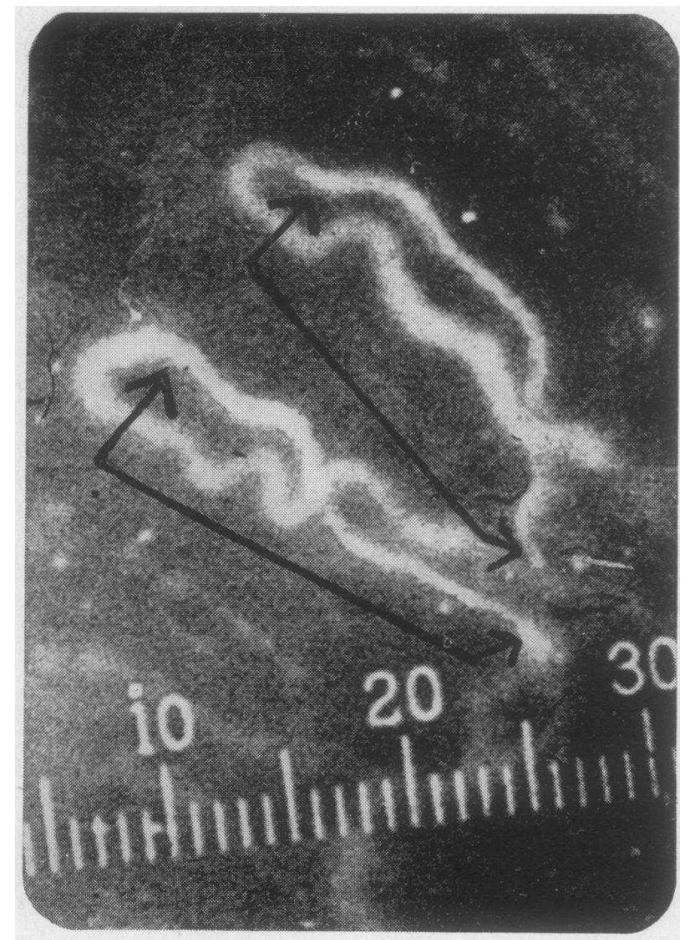

Fig. 2. Two Capillary Loops Taken from Figure 1 Arrows indicate the arterial segments $(160 \times)$. immediately prior to the development of the ischemia (this was not observed during normal vasomotion ) ; 4) the ischemia was interrupted by frequent momentary periods of blood flow; 5) the shortest duration of ischemia selected for the endpoint of the titration, 15 seconds, was usually five to 20 times longer than that observed during the control period of observation; 6 ) the ischemia was reproducible when the same quantity of epinephrine or nor-epinephrine was reinjected after a five minute interval.

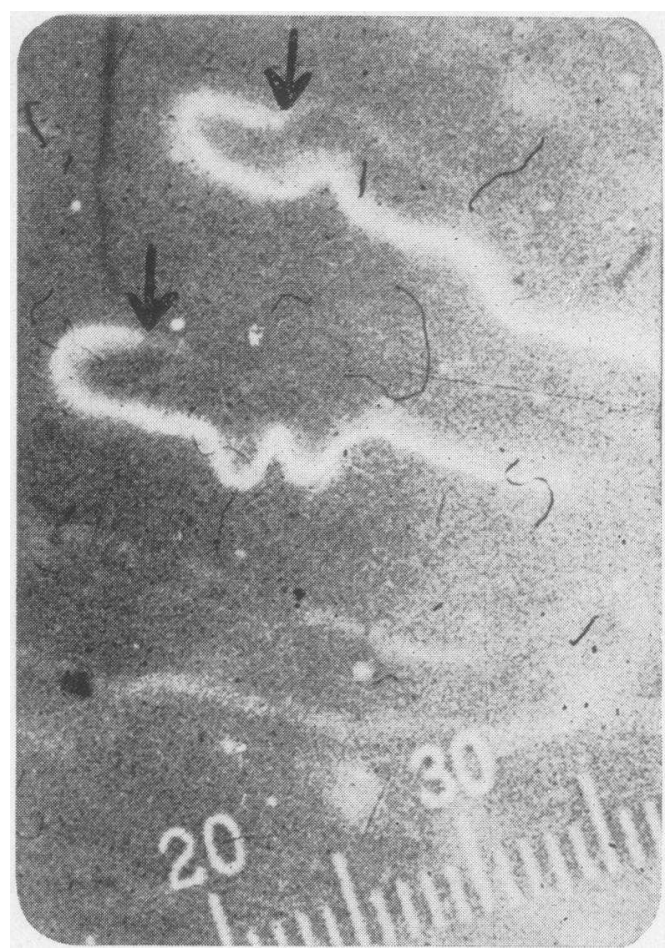

Fig. 3. Reaction Following 1.5 Gamma of EpiNEPHRINE, I.V.

Arrows indicate junction of arterial segments with venous segments $(160 \times)$.

It was usually impossible to visualize clearly the arterial system proximal to the terminal capillary loops. The possibility that the ischemia following the injection of epinephrine or nor-epinephrine was due to constriction of the parent metarteriole and not directly to constriction of the arterial segments of the capillary loops could not be excluded.

The capillary bed of the nailfold of the finger of a patient with normal blood pressure is reproduced in Figure 1, a microphotograph magnified 
TABLE I

Threshold reactivity of the arterial segments of the capillary loops of the nailfold in patients with normal blood pressure

\begin{tabular}{|c|c|c|c|c|c|c|c|}
\hline & $\begin{array}{c}\text { Blood } \\
\text { pressure }\end{array}$ & $\begin{array}{c}\text { Pulse } \\
\text { rate }\end{array}$ & $\begin{array}{c}\text { Threshold } \\
\text { level }\end{array}$ & $\begin{array}{l}\text { Duration } \\
\text { of effect }\end{array}$ & Drug* & Major diagnosis & Age \\
\hline $\begin{array}{r}1 \\
2 \\
\\
3 \\
4 \\
5 \\
6 \\
7 \\
8 \\
9 \\
10 \\
11 \\
12 \\
13 \\
14 \\
15 \\
16 \\
17\end{array}$ & $\begin{array}{c}m m . H g \\
130 / 58 \\
120 / 68 \\
\\
112 / 70 \\
122 / 70 \\
130 / 70 \\
140 / 70 \\
148 / 70 \\
130 / 74 \\
156 / 76 \\
130 / 80 \\
150 / 67 \\
136 / 68 \\
150 / 74 \\
120 / 60 \\
110 / 76 \\
160 / 86 \\
120 / 76\end{array}$ & $\begin{array}{c}\text { per min. } \\
78 \\
72 \\
\\
80 \\
88 \\
76 \\
78 \\
78 \\
80 \\
72 \\
106 \\
92 \\
80 \\
96 \\
72 \\
80 \\
88 \\
80\end{array}$ & $\begin{array}{l}\text { gamma } \\
1.5 \\
2.25 \\
1.5 \\
2.0 \\
1.5 \\
1.5 \\
1.75 \\
1.5 \\
1.5 \\
1.5 \\
1.0 \\
1.25 \\
1.5 \\
1.25 \\
1.25 \\
1.5 \\
1.25 \\
1.75\end{array}$ & $\begin{array}{l}\text { seconds } \\
15 \\
25 \\
25 \\
25 \\
25 \\
20 \\
20 \\
20 \\
30 \\
20 \\
20 \\
30 \\
30 \\
15 \\
30 \\
35 \\
30 \\
15\end{array}$ & $\begin{array}{l}\mathrm{E} \\
\mathrm{E} 1 \\
\mathrm{E} \\
\mathrm{E} \\
\mathrm{E} \\
\mathrm{E} \\
\mathrm{E} \\
\mathrm{E} \\
\mathrm{E} \\
\mathrm{E} \\
\mathrm{E} 1 \\
\mathrm{~N} \\
\mathrm{~N} \\
\mathrm{~N} \\
\mathrm{~N} \\
\mathrm{~N} \\
\mathrm{~N}\end{array}$ & $\begin{array}{l}\text { Pulmonary fibrosis and emphysema } \\
\text { Diabetes mellitus } \\
\text { Pernicious anemia } \\
\text { Post pneumonia } \\
\text { Pulmonary fibrosis and emphysema } \\
\text { Old cerebrovascular accident } \\
\text { Cerebral atherosclerosis } \\
\text { Diabetes mellitus } \\
\text { Cerebral atherosclerosis } \\
\text { Lymphosarcoma } \\
\text { Pulmonary fibrosis and emphysema } \\
\text { Arteriosclerotic heart disease, III C } \\
\text { Old cerebrovascular accident } \\
\text { Cerebral atherosclerosis } \\
\text { Paget's disease of bone } \\
\text { Schizophrenia } \\
\text { Old cerebrovascular accident }\end{array}$ & $\begin{array}{c}\text { years } \\
59 \\
46 \\
46 \\
49 \\
39 \\
75 \\
75 \\
62 \\
72 \\
73 \\
47 \\
59 \\
74 \\
62 \\
64 \\
57 \\
55 \\
76\end{array}$ \\
\hline
\end{tabular}

Mean $=1.51$ gamma

Standard deviation $=0.30$ gamma.

Standard error $=0.073$ gamma.

*Epinephrine-E; Levo epinephrine-E1; Levo nor-epinephrine-N.

TABLE II

Threshold reactivity of the arterial segments of the capillary loops of the nailfold in patients with essential hypertension

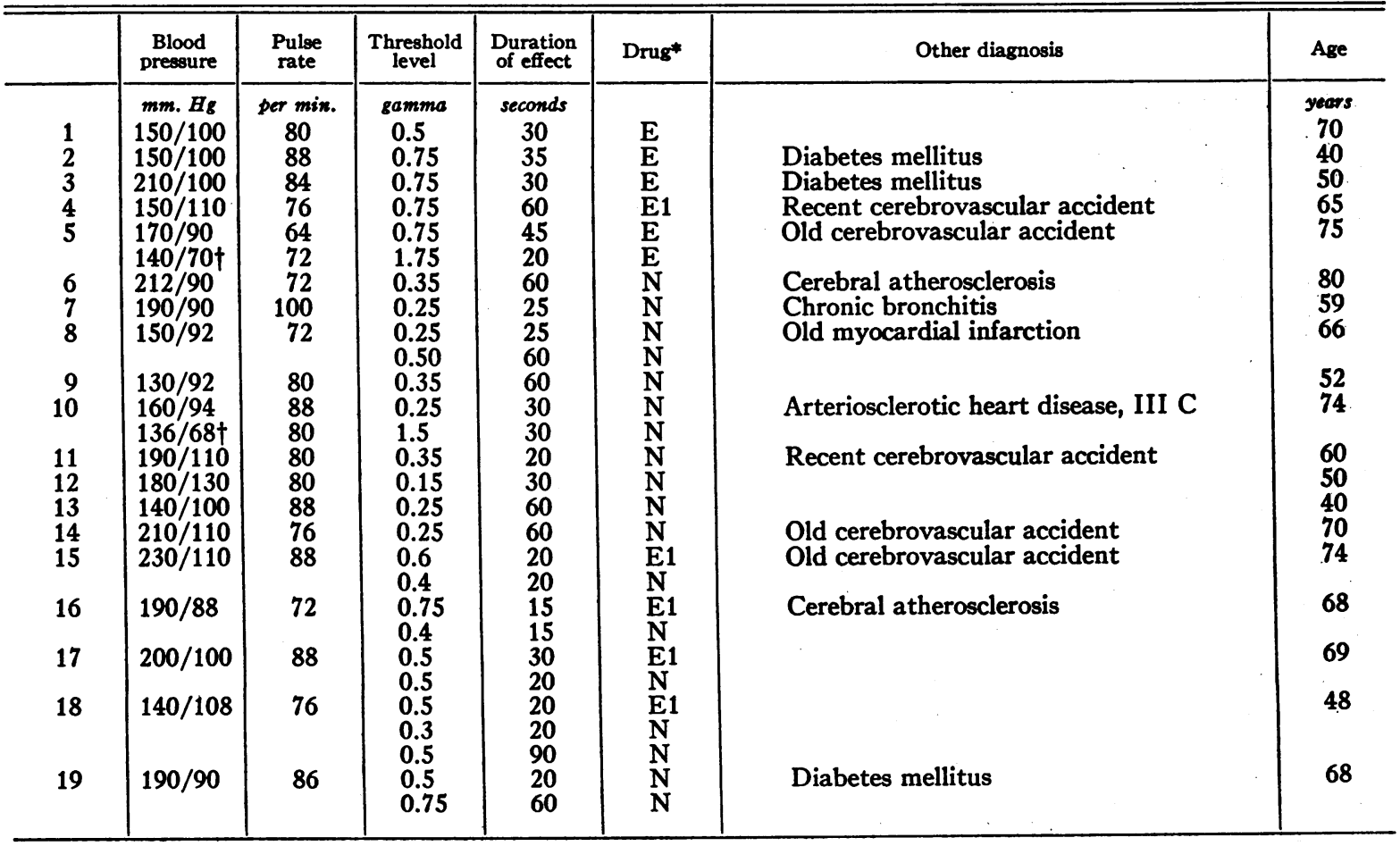

Mean $=0.45$ gamma.

Standard deviation $=0.17$ gamma.

Standard error $=0.036$ gamma.

* Epinephrine-E; Levo epinephrine-E1; Levo nor-epinephrine-N.

† Same case as the preceding one examined two and three weeks later, respectively. 
TABLE III

Threshold reactioity of the arterial segments of the capillary loops of the nailfold in patients with inadequate capillary blood flow

\begin{tabular}{|c|c|c|c|c|c|c|c|c|c|c|c|}
\hline $\begin{array}{c}\text { Blood } \\
\text { pressure }\end{array}$ & $\begin{array}{l}\text { Pulse } \\
\text { rate }\end{array}$ & $\begin{array}{c}\text { Thresh- } \\
\text { old } \\
\text { level }\end{array}$ & $\begin{array}{l}\text { Duration } \\
\text { of effect }\end{array}$ & Drug* & Skin & $\begin{array}{l}\text { Skin } \\
\text { color }\end{array}$ & $\begin{array}{l}\text { Rate } \\
\text { of flow }\end{array}$ & $\begin{array}{l}\text { Circ. } \\
\text { time }\end{array}$ & Sludge & Major diagnosis & Age \\
\hline$m m . H g$ & per min. & gamma & secs. & & & & & secs. & & & years \\
\hline $\begin{array}{l}118 / 60 \\
122 / 70 \dagger \\
96 / 76 \\
100 / 78\end{array}$ & $\begin{array}{r}120 \\
88 \\
86 \\
76\end{array}$ & \begin{tabular}{r|}
10.0 \\
1.5 \\
5.0 \\
4.0
\end{tabular} & $\begin{array}{l}10 \\
25 \\
20 \\
25\end{array}$ & $\begin{array}{l}\mathbf{E} \\
\mathbf{E} \\
\mathbf{E} 1\end{array}$ & $\begin{array}{l}\text { Cold } \\
\text { Warm } \\
\text { Cool } \\
\text { Cool }\end{array}$ & $\begin{array}{l}\text { Pale } \\
\text { Pink } \\
\text { Pink } \\
\text { Cyanotic }\end{array}$ & $\begin{array}{l}\text { Slow } \\
\text { Rapid } \\
\text { Slow } \\
\text { Slow }\end{array}$ & $\begin{array}{l}23 \\
15 \\
28 \\
26\end{array}$ & $\begin{array}{l}3 \times \\
1 \times x \\
3 \times \\
3 \times\end{array}$ & $\begin{array}{l}\text { Pneumonia } \\
\text { Convalescence } \\
\text { Cor pulmonale } \\
\text { Cor pulmonale }\end{array}$ & $\begin{array}{l}39 \\
60 \\
62\end{array}$ \\
\hline $110 / 80$ & 100 & $\begin{array}{l}4.0 \\
7.5\end{array}$ & 20 & $\mathbf{N}$ & Cool & Cyanotic & Slow & 23 & $2 \times$ & Arteriosclerotic heart dis- & 68 \\
\hline $126 / 80$ & 100 & 5.0 & 15 & $\mathbf{N}$ & Cool & Cyanotic & Slow & 25 & $3 x$ & Intestinal obstruction & 80 \\
\hline $\begin{array}{r}80 / 60 \\
160 / 80 \\
96 / 60 \\
110 / 60 \\
136 / 60\end{array}$ & $\begin{array}{r}120 \\
76 \\
80 \\
74 \\
80\end{array}$ & $\begin{array}{r}1.0 \\
5.0 \\
20.0 \\
4.0 \\
2.5 \\
2.5\end{array}$ & $\begin{array}{l}40 \\
20 \\
30 \\
30 \\
20\end{array}$ & $\begin{array}{l}\mathbf{N} \\
\mathbf{N} \\
\mathbf{E} \\
\mathbf{E}\end{array}$ & $\begin{array}{l}\text { Cool } \\
\text { Cold } \\
\text { Warm } \\
\text { Cool } \\
\text { Cool }\end{array}$ & $\begin{array}{l}\text { Cyanotic } \\
\text { Pale } \\
\text { Cyanotic } \\
\text { Cyanotic } \\
\text { Cyanotic }\end{array}$ & \begin{tabular}{|l|} 
Slow \\
Very slow \\
Slow \\
Slow \\
Slow
\end{tabular} & $\begin{array}{l}24 \\
26 \\
24 \\
28 \\
28\end{array}$ & $\begin{array}{l}3 \times \\
3 \times \\
2 \times \\
3 \times x \\
3 \times\end{array}$ & $\begin{array}{l}\text { Decompensated cirrhosis } \\
\text { Old cerebrovascular accident } \\
\text { Parkinsonism } \\
\text { Cerebral atherosclerosis } \\
\text { Cerebral atherosclerosis }\end{array}$ & $\begin{array}{l}65 \\
55 \\
65 \\
90 \\
86\end{array}$ \\
\hline
\end{tabular}

* Epinephrine-E; Levo epinephrine-E1; Levo nor-epinephrine-N.

$\dagger$ Same case as the preceding one examined ten days later.

80 times. Figure 2 is a higher power photograph, magnified 160 times, of two of the capillary loops. with arterial segments approximately 8 microns in diameter. The successive injection of 0.25 , 0.50 , and 0.75 gamma of epinephrine at five minute intervals produced no visible effect. The injection of 1.0 and 1.25 gamma of epinephrine each produced a transient increase in the vasomotion process but the capillary ischemia persisted no longer than eight and ten seconds respectively. Eighteen seconds following the intravenous administration of 1.5 gamma of epinephrine, constriction of the arterial segments of the loops occurred as seen in Figure 3, which persisted more than 15 seconds. This dose, 1.5 gamma, indicated the "threshold" quantity and was recorded as the endpoint.

The threshold capillary reactivities of patients with different blood pressures and adequate capillary blood flow are recorded in Tables I and II. The patients are divided into two major groups, those with normal blood pressure (Table I) and those with essential hypertension (Table II). For both epinephrine and nor-epinephrine, the threshold reactivity of the capillary bed in the nailfold of 17 individuals with normal blood pressure ranged from 1.0 to 2.25 gammas, with a mean of 1.51 gammas and a standard deviation of 0.30 gamma (Table I). The threshold reactivity of the capillary bed of 19 individuals with essential hypertension ranged from 0.5 to 0.75 gamma, with a mean of 0.65 gamma and a standard deviation of 0.12 gamma for epinephrine; and for norepinephrine from 0.15 to 0.50 gamma, with a mean of 0.34 gamma and a standard deviation of 0.09 gamma (Table II).

When capillary blood flow was inadequate, as indicated by coolness, pallor, or cyanosis of the skin, slowing of the capillary blood flow, clumping of the red blood cells, and prolongation of the circulation time, there was a wide range of "apparent" reactivity. Thus the threshold reactivity of the capillary bed in the nailfold of 10 patients with evidence of inadequate capillary flow ranged from 2.5 to 20.0 gammas for both epinephrine and nor-epinephrine (Table III).

\section{DISCUSSION}

The minute vascular bed of the nailfold is sensitive to circulating epinephrine and nor-epinephrine. The threshold reactivity of the arterial segments of these capillary loops can be visually "titrated" with epinephrine injected intravenously, and the results fall within a fairly narrow range, provided there is no interference with the blood flow to the capillary bed.

In the presence of an adequate capillary blood flow, the arterial segments of the terminal capillary loops of the nailfold of patients with essential hypertension exhibit a hyper-reactivity to circulating epinephrine and nor-epinephrine when compared with the capillary loops of subjects with normal 
blood pressures $(t=13)$. The arterial segments of the capillary loops of the nailfold of patients with normal blood pressure appear to be equally reactive to epinephrine and nor-epinephrine $(t=$ 1.1), whereas the capillary loops of patients with essential hypertension appear more reactive to nor-epinephrine than to epinephrine $(t=6.4)$.

The mechanism of the hyper-reactivity in patients with hypertensive vascular disease is conjectural. A small quantity of epinephrine is injected intravenously ( 0.1 to $0.8 \mathrm{cc}$.), acts rapidly upon the vascular bed, and is quickly inactivated. In disease states in which the effective concentration of the circulating epinephrine is reduced, the effect of the epinephrine is thereby altered. This will occur when the injected epinephrine is diluted to a greater volume (increased blood volume), or impeded from reaching the periphery (slow peripheral blood flow, low cardiac output). Changes in skin temperature would also alter capillary reactivity. Since the blood volume, the peripheral blood flow, the cardiac output, the circulation time, and the skin temperature are not significantly altered in hypertensive vascular disease (14-20), the difference in vascular reactivity to epinephrine probably is not attributable to these factors. The increased vascular reactivity in hypertensive vascular disease appears, justifiably, to be directly referable to the capillary bed. Epinephrine and norepinephrine appear to act upon the capillary bed by intensifying the normal vasomotion process. Vasomotion is usually increased in patients with essential hypertension. The hyper-reactivity of the arterial segments of the capillary bed to epinephrine and nor-epinephrine that occurs in essential hypertension may therefore be solely a reflection of this fundamental increase in vasoconstrictor activity.

It should again be stressed that the results presented apply only to the arterial segments of the terminal capillary loops of the nailfold of the finger.

\section{SUMMARY AND CONCLUSIONS}

1. The arterial segments of the capillary loops of the nailfold of the finger are sensitive to circulating epinephrine and nor-epinephrine. The threshold vasoconstrictor reactivity is fairly constant under the conditions outlined, and falls within a narrow range in persons with normal blood pressure and essential hypertension, when capillary blood flow is adequate.

2. The arterial segments of the terminal capillary loops in the nailfold of patients with essential hypertension are hyper-reactive to circulating epinephrine; this hyper-reactivity is even more marked to circulating nor-epinephrine.

3. These changes in epinephrine reactivity are referred directly to the capillary bed because the blood volume, the cardiac output, the peripheral blood flow, the circulation time, and the skin temperatures do not differ significantly from normal in individuals with essential hypertension.

4. Vasomotion of the capillary bed is intensified in patients with hypertensive vascular disease. The hyper-reactivity of the capillary bed to circulating epinephrine and nor-epinephrine in essential hypertension may be solely a reflection of this fundamental increase in vasoconstrictor activity.

5. The results and conclusions apply only to the capillary loops of the nailfold of the finger when the capillary blood flow is adequate.

\section{REFERENCES}

1. Gordon, W., and Levitt, G., Blood pressure changes in normals and in hypertensives after intravenous epinephrine and histamine. J. Clin. Invest., 1935, 14, 367.

2. Pickering, G. W., and Kissin, M., The effects of adrenaline and of cold on the blood pressure in human hypertension. Clin. Sc., 1936, 2, 201.

3. Fatherree, T. J., and Hines, E. A., Jr., The blood pressure response to epinephrine administered intravenously to subjects with normal blood pressure and to patients with essential hypertension. Am. Heart J., 1938, 16, 66.

4. Judson, W. E., Culbertson, J. W., Tinsley, C. M., Litter, J., and Wilkins, R. W., The comparative effects of small intravenous doses of epinephrine upon arterial pressure and pulse rate in normotensive subjects and in hypertensive patients before and after thoracolumbar sympathectomy. J. Clin. Invest., 1950, 29, 1405.

5. Judson, W. E., Epstein, F. H., and Wilkins, R. W., The comparative effects of small intravenous doses of $l$-nor-epinephrine upon arterial pressure and pulse rate in normotensive subjects and in hypertensive patients before and after thorocolumbar sympathectomy. J. Clin. Invest., 1950, 29, 1414.

6. Goldenberg, M., Pines, K. L., Baldwin, E. de F., Greene, D. G., and Roh, C. E., The hemodynamic response of man to nor-epinephrine and epinephrine and its relation to the problem of hypertension. Am. J. Med., 1948, 5, 792. 
7. Clough, P. W., A study of the cardiovascular reaction to epinephrine. Epinephrine sensitiveness in patients with hypertension. Bull. Johns Hopkins Hosp., 1920, 31, 266.

8. Lee, R. E., and Holze, E. A., The peripheral vascular system in the bulbar conjunctiva of young normotensive adults at rest. J. Clin. Invest., 1950, 29, 146.

9. Lee, R. E., and Holze, E. A., Peripheral vascular hemodynamics in the bulbar conjunctiva of subjects with hypertensive vascular disease. J. Clin. Invest., 1951, 30, 539.

10. Lewis, T., The blood vessels of the human skin and their responses. Shaw, London, 1927, 322 pp.

11. Zweifach, B. W., The character and distribution of the blood capillaries. Anat. Rec., 1939, 73, 475.

12. Chambers, R., and Zweifach, B. W., Topography and function of the mesenteric capillary circulation. Am. J. Anat., 1944, 75, 173.

13. Chambers, R., and Zweifach, B. W., Funtional activity of the blood capillary bed, with special reference to visceral tissue. Ann. New York Acad. Sci., 1946, 46, 683.
14. Allen, E. V., Barker, N. W., Hines, E. A., Peripheral Vascular Diseases. W. B. Saunders Co., Philadelphia, 1946.

15. Prinzmetal, M., and Wilson, C., The nature of the peripheral resistance in arterial hypertension with special reference to the vasomotor system. J. Clin. Invest., 1936, 15, 63.

16. Goldring, W., and Chasis, H., Hypertension and Hypertensive Diseases. The Commonwealth Fund, New York, 1944.

17. Pickering, G. W., The peripheral resistance in persistent arterial hypertension. Clin. Sc., 1936, 2, 209.

18. Steele, J. M., and Kirk, E., The significance of the vessels of the skin in essential hypertension. J. Clin. Invest., 1934, 13, 895.

19. Stewart, H. J., Evans, W. F., Haskell, H. S., and Brown, H., The peripheral blood flow and rectal and skin temperatures in hypertension. Am. Heart J., 1946, 31, 617.

20. Blumgart, H. L., and Weiss, S., Studies on the velocity of blood flow. J. Clin. Invest., 1927, 4, 173. 